\title{
Arthroscopic management of anterior inferior iliac spine impingement: a systematic review
}

\author{
Alberto Fioruzzi ${ }^{1}$ \\ Eugenio Jannelli1 \\ Alessandro Ivone ${ }^{1}$ \\ Simone Perelli ${ }^{1}$ \\ Andrea Fontana ${ }^{2}$ \\ Alessio Giai Via $^{3}$ \\ 1 Clinica ortopedica e traumatologica, Fondazione \\ IRCCS Policlinico San Matteo, Pavia, Italy \\ 2 Ortopedia 1, COF Lanzo Hospital, Lanzo d'Intelvi, \\ (CO), Italy \\ 3 Department of Orthopaedics and Traumatology, \\ Hip Surgery Center, IRCCS Policlinico San Donato, \\ Milan, Italy
}

\author{
Corresponding author: \\ Alberto Fioruzzi \\ Clinica ortopedica e traumatologica, \\ Fondazione IRCCS Policlinico San Matteo \\ Viale Camillo Golgi 19 \\ 27100 Pavia, Italy \\ Tel.: +39 3289222682 \\ E-mail: alberto.fioruzzi@gmail.com
}

\section{Summary}

Introduction: Subspine impingement is characterized by a prominent anterior inferior iliac spine that creates an abnormal contact with the distal femoral neck during hip movements. Currently, the clinical picture and diagnostic criteria are still being refined for these conditions. This study aimed to systematically review the literature on the subspine impingement arthroscopic treatment to elucidate the indication for and clinical outcome of surgical arthroscopic decompression of the anterior inferior iliac spine.

Methods: The PubMed and Web of Science library were searched for any publications using the terms "subspine impingement" and "subspine impingement hip" in the "Title, Abstract, Keywords" field. The search was extended to all the literature on the topic.

Results: Overall, 127 studies were initially retrieved; ultimately, 8 studies were included examining 361 hips. The arthroscopic decompression of the anterior inferior iliac spine resulted in a mean 18.5 degrees improvement in flexion, as well as im- provements in pain and functional outcome scores. Conclusion: This review suggests that arthroscopic decompression of a symptomatic anterior inferior iliac spine deformity can provide excellent outcomes at short-term follow-up in the absence of significant complications and recurrences. Level of evidence: Illa.

KEY WORDS: FAl, hip arthroscopy, impingement, subspine.

\section{Introduction}

Intra-articular causes of hip pain such as femoral acetabular impingement syndrome and acetabular labral tears have become well-known pathologies in younger non-arthritic individuals ${ }^{1-3}$. Arthroscopic procedures have shown excellent outcomes with returning individuals to pre-injury levels of function and sports activity ${ }^{4-6}$.

Recently, literature has identified extra-articular causes of hip impingement (EAHI) that are associated with patients who have poor outcomes to hip arthroscopic procedures ${ }^{7}$. Extra-articular hip impingement, which may coexist with intra-articular femoroacetabular impingement syndrome, is caused by an abnormal contact between the extra-articular regions of the femoral neck and the pelvis ${ }^{8}$. Subspine impingement (SSI) is undoubtedly one of the best-studied cause of extra-articular hip impingement.

SSI is caused by a prominent anterior inferior iliac spine (AIIS) that abuts the distal femoral neck during hip flexion ${ }^{9}$. SSI is thought to be caused by an excessive muscular activity of the rectus femoris during knee flexion with an extended hip resulting in an avulsion injury of the AlIS. Through the healing process, the inferior displacement of the apophysis may lead to a malunion which often results in an enlarged bony protrusion ${ }^{10}$. Avulsion injuries are common in adolescent athletes, especially in running sports and sports involving kicking ${ }^{11}$. Avulsion injuries to the AlIS are reported to be the second most common with ischial avulsions being the most common ${ }^{12}$.

De Sa et al. ${ }^{7}$ suggest that this condition is more common in younger active males (age range 14 to 30 years). Patients often complain of an anterior hip or groin pain that is worsened by active hip flexion and repetitive sports activities.

Arthroscopic decompression of an impinging AllS also termed "spinoplasty"13 has been reported recent- 
$\mathrm{ly}^{9,14,15}$. The presence of an anterior focal synovitis and a labral bruising in the area of the anterior inferior iliac spine, as well as the presence of a bony bump, which represents the extension of the prominence to the anterior-superior acetabular rim, confirm the diagnosis of $\mathrm{SSI}^{9,14}$.

The present review and its procedures were organized, conducted and reported following the Preferred Reporting Items for Systematic Reviews and MetaAnalyses (PRISMA) guidelines ${ }^{16}$.

We aimed to elucidate:

1. the clinical outcome of arthroscopic surgical decompressione of the anterior inferior iliac spine at short to medum follow-up

2. defining the best imaging modalities to assess the anterior inferior iliac spine morphology

3. whether there is a difference between the sexes. This review is written according to the ethical standards of the Journal ${ }^{17}$.

\section{Material and methods}

Our study group searched the PubMed database and Web of Science using the terms "subspine impinge- ment", "subspine impingement hip" in the "all terms" field and this produced 127 results. The abstracts were then reviewed to determine suitability for inclusion in the review.

The research question and inclusion/exclusion criteria were determined a priori and included English-language studies of all levels of evidence on humans. We excluded studies not reporting arthroscopic surgical outcomes data, such as radiographic studies, review articles, and instructional course lectures. Of particular interest were the techniques of subspine impingement arthroscopic treatment and the results produced, measured by most papers as the improvement in the value of visual analog scale, modified Harris hip score and range of motion in flexion. A total of 8 articles met the inclusion criteria, with Figure 1 outlining the screening process.

The principal conclusions drawn from the papers were then compared to produce the findings of this review. Descriptive statistics of the eligible studies were performed. A meta-analysis was not feasible because there were no intra-study comparison data as the studies showed variability in patient-reported outcome measures. Formal quality scoring of the studies was not performed because of the quality of evidence (i.e., case series and reports) produced by the search.

\section{Studies Identified Through PubMed and Web of Science search}

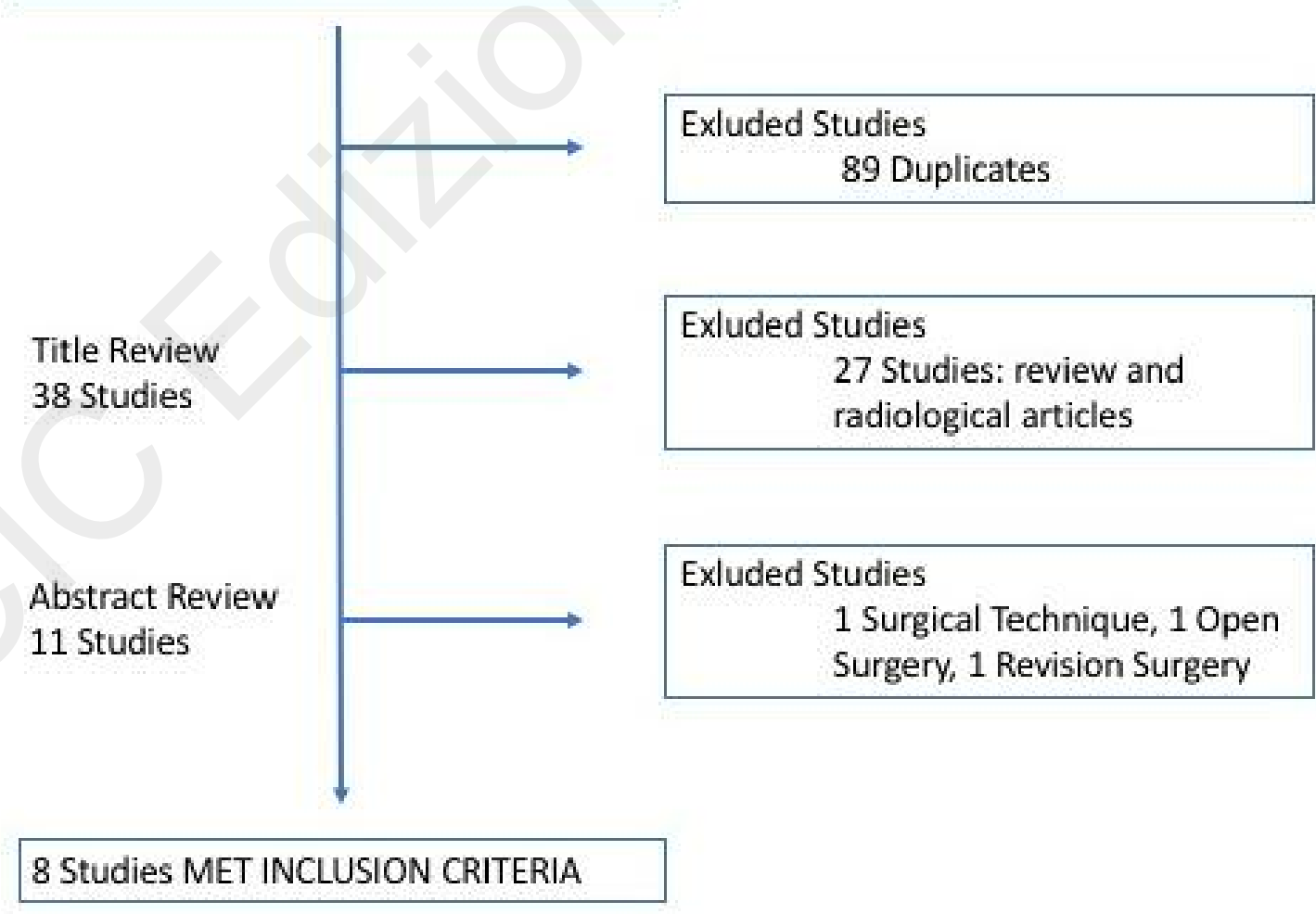

Figure 1. Systematic screening process. 


\section{Results}

Of the eight included studies $9,13,14,18-22,3$ were case series, 4 were case reports, and one study was a retrospective case-control, totaling 312 patients (361 hips). Patients were aged younger than 30 years and were predominantly male, but two studies were conducted only on female patients. The mean follow-up was lower than 24 months with just a study with a mean follow-up of 35 months. Table I outlines additional individual study demographic information.

The primary reported indications for surgical treatment of SSI, summarized in Table II, included persistent pain after nonoperative treatment, either specific hip physical therapy protocol or intraarticular injection, hip flexion and pain with palpation of the AlIS. In all the studies an indication for arthroscopic decompression was the presence of imaging, X-ray or CT scan, showing a prominent AlIS. There were no reported contraindications for surgery.

The main results in clinical outcomes, functional outcome and complications for each study analized are reported in Table III.

All the studies show a fair increase in the modified Harris Hip Score from the preoperative analisys to the postoperative time, ranging from a minimum mean improvement of 18 points to a maximum mean improvememnt of 34.2 points. The range of flexion also increased in all studies by a mean of $23.4^{\circ}$, unfortunately only two studies reported the preoperative and postoperative values of the VAS with a significant mean improvement. None of the study reported a major complication at the final follow-up.

\section{Discussion}

There is currently no standardized protocol treatment described in the literature for the management of subspine impingement. Several Authors reported their results in the arthroscopic decompression of a prominent AIIS, but there aren't studies of a high level of evidence to support this treatment.

This is the first systematic review addressing only the arthroscopic treatment of subspine impingement. Our review suggests that short-term outcomes of arthroscopic decompression of a prominence of the AllS are favorable for patients with characteristic anterior hip pain with suggestive imaging and history of symptoms.

Hetsroni et al. ${ }^{1}$ developed a classification system based on CT scan with three level of increasing deformity and associated the ROM limits witch each type. Type 1 AlIS morphology consists of a smooth ilium wall without a bony prominence between the caudal level of the AIIS and the acetabular rim. Type 2 AIIS morphology includes an osseous prominence extending from the inferior border of the AIIS up to the acetabular rim. Type 3 AIIS morphology comprises of a bony prominence extending distally to, or beyond, the anterior-superior acetabular rim.
A study by Krueger et al. ${ }^{23}$ investigated the role of the conventional AP pelvis X-ray in evaluating the projection of the AlIS. They concluded that a precise distinction of the AlIS morphology was not possible in the AP view, and in their cases a distal extension of the AIIS below the anterior acetabular rim was related to type II and III AlIS morphologies in the CT reconstruction.

However, the false-profile radiographic view was the most accurate and reproducible view to show AlIS morphology in a study by Schindler et al. ${ }^{24}$.

Non-surgical intervention such as activity modification, rehabilitation, and therapeutic injections ${ }^{25}$ may be prescribed first, but their efficacy has not been investigated 7 . Physical therapy may include hip strengthening with avoidance of hip flexion greater than 70 degrees $^{26}$. Exercises to control anterior pelvic tilt protect the proximal rectus tendon from impingement injury leading to tendinopathy are suggested by some Authors. Some patients may be resistant to conservative treatment and require surgical interventions.

In the past, decompression of symptomatic AlIS prominence was described through the Smith-Petersen approach ${ }^{27}$, either as a single procedure or after arthroscopic exploration of the joint but recently, the concept of arthroscopic AIIS decompression has been introduced in a case report study. Using standard anterolateral and mid-anterior portals, with an anterosuperior capsular dissection the AlIS is exposed from 1:30 to 2:00 o'clock. The capsulotomy should not be carried too medially, to avoid significant complication, such as nerve injury or fluid extravasation $^{28}$. A $5.5 \mathrm{~mm}$ burr is used to decompress the bone. Although more may be needed in post-traumatic cases, bone removal of up to $1.5 \mathrm{~cm}$ in cephalad and anterior directions is usually adequate ${ }^{14}$. This amount of resection reduces the risk of rectus detachment. On the other hand, a window through the tendon fibers may be required for more extensive resection, yet without any adverse sequelae ${ }^{14,18}$. A post-operative prophylaxis against heterotopic ossification is recommended for the first 3 to 4 weeks ${ }^{18}$.

Larson et al. ${ }^{9}$ were the first to propose the idea of subspine impingement and included three representative cases after arthroscopic subspine decompression. The mean follow-up was 12 months, and the mHHS improved from a mean of 76 points preoperatively to 94 points postoperatively.

In the series by Hapa et al. ${ }^{14}$ there was an approximate 22.2-point increase in the postoperative modified Harris Hip Score and a significant decrease of the VAS score, and none of the patients complained of a hip flexion deficit. They described a bare area of the AIIS anteriorly and inferomedially consistently present, and that represents a "safe zone" of resection to avoid a rectus femoris tendon damage. Their clinical series of arthroscopic subspine decompressions is the largest in the literature, and their results indicate that the risk for postoperative hip flexion weakness and risk for rectus femoris rupture are minimal. 


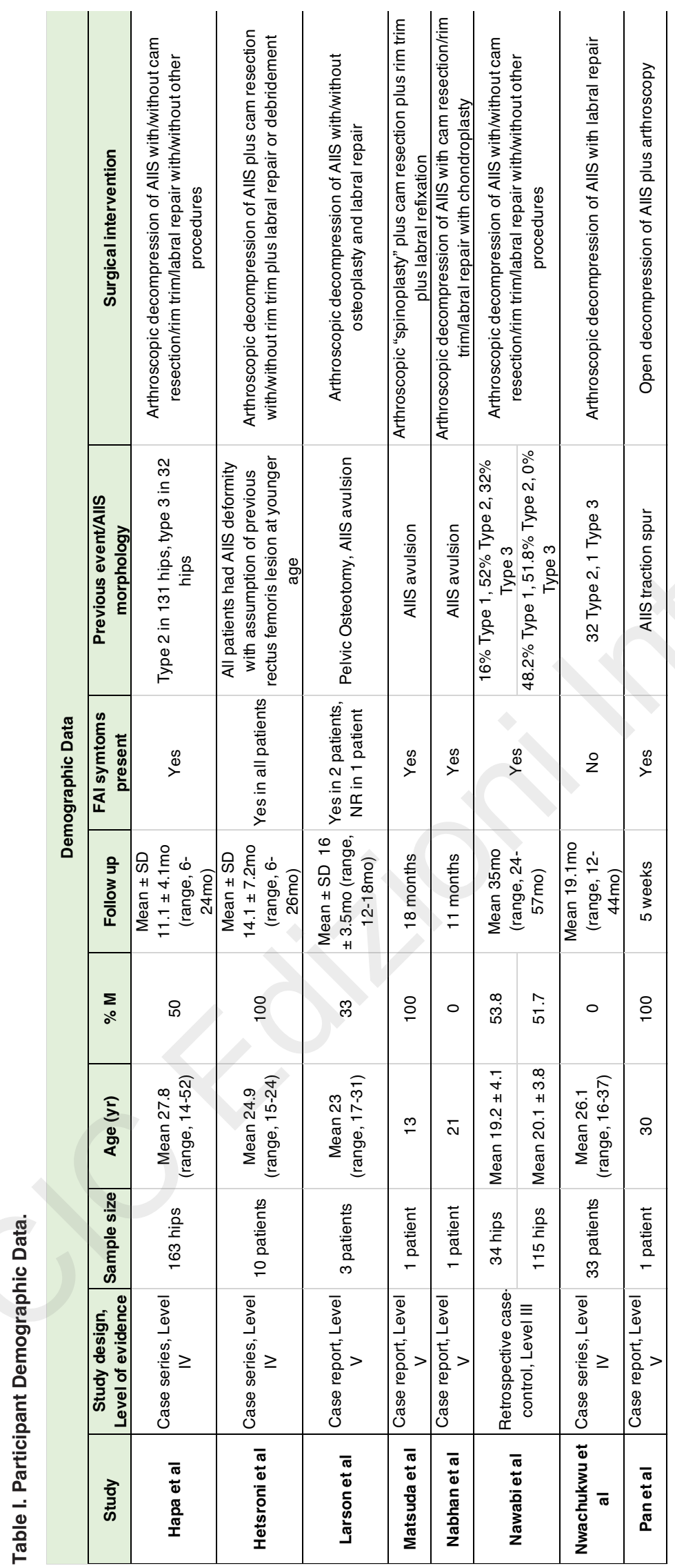


Table II. Reported Diagnostic Criteria.

\begin{tabular}{l|l}
\multicolumn{1}{c|}{ Study } & \multicolumn{1}{c}{ Diagnostic Criteria } \\
\hline Hapa et al. & $\begin{array}{l}\text { Terminal hip flexion pain and limitations, tenderness to palpation of AllS, imaging showing type } 2 \text { or } 3 \\
\text { AllS, intraoperative focal bruising and synovitis in region of AlIS }\end{array}$ \\
\hline Hetsroni et al. & $\begin{array}{l}\text { Anterior hip pain, tenderness over AllS, limited and painful terminal flexion, pain not resolved with intra- } \\
\text { articular injection, prominent AllS on imaging }\end{array}$ \\
\hline Larson et al. & Painful limited flexion, limited response to intra-articular injection, prominent AllS on imaging \\
\hline Matsuda et al. & Positive impingement sign/FABER, malunited prominent AllS \\
\hline Nabhan et al. & Anterior hip pain, positive subspine impingement test, terminal hip flexion pain, prominent AllS on X-rays \\
\hline Nawabi et al. & $\begin{array}{l}\text { Terminal hip flexion pain, positive FADIR test, alpha angle }>50^{\circ}, \text { symptoms refractory to nonoperative } \\
\text { treatment }\end{array}$ \\
\hline Nwachukwu & $\begin{array}{l}\text { Anterior hip pain, positive subspine impingement test, prominent AllS on CT scan, failure of a hip-specific } \\
\text { physical therapy protocol for a minimum of 3 months, positive extra-articular corticosteroid injection }\end{array}$ \\
\hline et al. & Painful flexion with rotation, prominent AllS on imaging \\
\hline
\end{tabular}

Table III. Clinical Outcomes and Complications.

\begin{tabular}{|c|c|c|c|c|c|c|c|c|}
\hline \multirow[b]{2}{*}{ Study } & \multirow[b]{2}{*}{ Case No. } & \multicolumn{2}{|c|}{ Flexion } & \multicolumn{2}{|c|}{ MHHS } & \multicolumn{2}{|c|}{ VAS } & \multirow{2}{*}{ Complications } \\
\hline & & Preoperative & Postoperative & Preoperative & Postoperative & Preoperative & Postoperative & \\
\hline Hapa et al. & \begin{tabular}{|c|}
163 hips \\
$(150$ \\
patients) \\
\end{tabular} & & No deficit & $63.1(21-90)$ & $85.3(37-100)$ & $4.9(0.1-8.6)$ & $1.9(0-7.8)$ & NR \\
\hline Hetsroni et al. & 10 & $98,5(90-110)$ & $117(110-130)$ & $64.2(41-96)$ & $98.4(96-100)$ & NR & NR & None \\
\hline Larson et al. & 3 & $105(100-110)$ & $126,6(125-130)$ & $75,66(74-79)$ & $93,66(85-100)$ & $6,85(4,85-8)$ & $1,13(0-1,75)$ & None \\
\hline Matsuda et al. & 1 & NR & NR & NAHS, 22 & NAHS, 98 & NR & NR & 1 asymptomatic $\mathrm{HO}$ \\
\hline Nabhan et al. & 1 & 90 & No deficit & NR & $\mathrm{NR}$ & $\mathrm{NR}$ & $\mathrm{NR}$ & None \\
\hline \multirow[t]{2}{*}{ Nawabi et al. } & 34 & NR & NR & $66.7 \pm 11.2$ & $89 \pm 14.6$ & NR & NR & $\begin{array}{c}3 \text { patients revision at a } \\
\text { mean of } 32 \text { months } \\
\text { postop }\end{array}$ \\
\hline & 115 & NR & NR & NR & $88.2 \pm 14.4$ & NR & NR & $\begin{array}{c}8 \text { patients revision at a } \\
\text { mean of } 34 \text { months } \\
\text { postop }\end{array}$ \\
\hline $\begin{array}{l}\text { Nwachukwu } \\
\text { et al. }\end{array}$ & 33 & NR & NR & $57.2 \pm 15.3$ & $79.5 \pm 19$ & NR & NR & NR \\
\hline$\overline{\text { Pan et al. }}$ & 1 & 90 & 120 & NR & NR & NR & NR & None \\
\hline
\end{tabular}

These results were consistent with the other studies as well, with Hetsroni et al. ${ }^{18}$ showing improvement of 34.2-point postoperatively on the modified Harris Hip Score and an increase of 18.5 degrees in hip flexion. Pan et al. ${ }^{22}$ reported in their case report a postoperative increase of thirty degrees in hip flexion, but they did not perform an analysis of the functional outcome of the procedure.

In one study that used the Non-Arthritic Hip Score, the Authors ${ }^{13}$ reported an improvement from 22 points preoperatively to 98 points postoperatively resulted from decompression of the AlIS. All patients reported improved pain, and no significant complications were reported. Asymptomatic heterotrophic ossification was described in one patient ${ }^{13}$.

In the only level III study by Nawabi et al. ${ }^{20}$ there was no evidence of differences in outcome scores be- tween the kicking athlete group and the nonkicking group. In their research, the $8.8 \%$ of patients in the kicking athlete group required a revision surgery and $7 \%$ of the patient in the control group. Nawabi et al. ${ }^{20}$ showed in their study a higher prevalence of type II and III AIIS morphologies in soccer players (84\%) than in a control group of nonkicking athletes (52\%). These findings suggest that the repetitive kicking may produce subclinical avulsion injuries or traction apophysitis, contributing to the gradual development of AllS hypertrophy or elongation, as identified in this group. Further, supportive evidence includes the fact that the majority $(72 \%)$ of the unilateral athletes in both cohorts required operative treatment in their dominant extremity, suggesting that the forceful, repetitive rectus femoris contractions in their dominant limb contributed to the development of their AlIS 
morphology and resultant subspine impingement. Also in the paper by Hetsroni et al. ${ }^{18} 70 \%$ of the patients were involved in specific sports requiring repetitive kicking or sprinting, and all related the initiation of their symptoms to hip flexion injuries.

The published outcomes of arthroscopic treatment of SSI are consistently good with documented preservation of the rectus femoris function as a hip flexor. However, they are restricted by the fact that SSI decompression is rarely performed in isolation, as it is frequently done in association with many concomitant procedures, typically for FAI syndrome. Moreover, the studies report just results from high-volume hip arthroscopists, rendering the generalizability of results still unknown. Future research of higher level of evidence should investigate in more detail the interaction of SSI and FAI and provide guidelines as to when to address one or both during the same surgery.

Nwachukwu et al. ${ }^{21}$ were the first Authors who reported on the outcomes of only arthroscopic subspine decompression. His study findings confirmed that a subset of patients presented with hip pain that is attributable to isolated subspine impingement. This result was corroborated by the fact that the mean alpha angle in this cohort was $50.6 \pm 8.6^{\circ}$, thereby suggesting that these patients did not have a cam morphology. They also found that all of the patients at their institution who had undergone AlIS decompression without associated FAI surgery were female. The study by Amar et al. ${ }^{29}$, which aimed at describing the size, location and position of the anterior inferior iliac spine, showed no significative difference between men and women in length, height; vertical, horizontal and straight distances between the most anteroinferior prominent point of the AIIS and the acetabular rim when normalized to patient's height and BMI. They only found a statistical significance difference in the width of the AllS between sexes, with values higher in the male sex whether the results were normalized or not.

Nwachukwu et al. do not explain in their study whether the female population included patients doing activities requiring high ROM such as dance or yoga. Future study could analize if there is an actual difference between sexes in the pelvic tilt or capsular laxity that can predispose to subspine impingement.

The study by Nawabi et al. ${ }^{20}$ was the only one to report a percentage of arthroscopic revision in both groups of patients analyzed. The causes of reoperation were mostly related to a residual hip impingement or failure of the intraarticular procedure, such as adhesions, residual cam deformity and the presence of a prominent anchor.

In a study by Larson et al. ${ }^{30}$ on arthroscopic hip revision surgery, $45.9 \%$ (39 hips) of the patients had a prominent/low AlIS extending to or caudal to the acetabular rim.

The limitations of this review depend mainly on the quality of the included studies. These barriers include, but are not limited to, the following: retrospective nature; small sample size; lack of control groups, restrict statistical comparison; incomplete data; potential concomitant diagnoses; and variable outcome measures reported. It has not escaped notice that although such outcome scores as the modified Harris Hip Score were used, for example, its applicability as a validated patient-reported outcome measure for patients undergoing hip arthroscopic surgery is questionable. Challenges exist, regarding definitive history, physical examination, and validated imaging findings for all conditions, having been described relatively recently.

\section{Conclusion}

This review suggests that arthroscopic decompression of a symptomatic anterior inferior iliac spine deformity can provide excellent outcomes at short-term follow-up in the absence of significant complications and recurrences.

\section{References}

1. Hetsroni I, Poultsides L, Bedi A, Larson CM, Kelly BT. Anterior inferior iliac spine morphology correlates with hip range of motion: a classification system and dynamic model. Clin Orthop Relat Res. 2013 Aug;471(8):24972503. Available from: http://www.pubmedcentral.nih.gov/ articlerender. . cgi ?artid=3705064\&tool=pmcentrez\&rendertype $=$ abstract

2. Ganz R, Parvizi J, Beck M, Leunig M, Nötzli H, Siebenrock KA. Femoroacetabular impingement: a cause for osteoarthritis of the hip. Clin Orthop Relat Res. 2003 Dec; (417):112-120. Available from: http://www.ncbi.nlm. nih.gov/pubmed/14646708

3. Ito K, Minka M a, Leunig M, Werlen S, Ganz R. Femoroacetabular impingement and the cam-effect. A MRI-based quantitative anatomical study of the femoral head-neck offset. J Bone Joint Surg Br. 2001;83(September 1997): 171-176.

4. Kemp JL, Collins NJ, Makdissi M, Schache AG, Machotka Z, Crossley K. Hip arthroscopy for intra-articular pathology: a systematic review of outcomes with and without femoral osteoplasty. Br J Sports Med. 2012 Jul;46(9):632643. Available from: http://www.ncbi.nlm.nih.gov/pubmed/ 22194221

5. Clohisy JC, St John LC, Schutz AL. Surgical Treatment of Femoroacetabular Impingement: A Systematic Review of the Literature. Clin Orthop Relat Res. 2010 Feb 15;468 (2):555-564. Available from: http://www.ncbi.nlm. nih.gov/ pubmed/19830504

6. Papalia R, Del Buono A, Franceschi F, Marinozzi A, Maffulli N, Denaro V. Femoroacetabular impingement syndrome management: arthroscopy or open surgery? Int Orthop. 2012 May 22;36 (5):903-914. Available from: http://www.ncbi.nlm.nih. gov/pubmed/22190060

7. Ayeni OR. Extra-articular hip impingement: a systematic review examining operative treatment of psoas, subspine, ischiofemoral, and greater trochanteric/pelvic impingement. Arthroscopy. 2014;30(8):1026-1041. Available from: http://dx.doi.org/10.1016/j.arthro. 2014. 02.042

8. Bardakos N V. Hip impingement: beyond femoroacetabular. J Hip Preserv Surg. 2015;2(3):206-223. Available from: https://academic.oup.com/jhps/article-lookup/doi/ 10.1093/jhps/hnv049 
9. Larson CM, Kelly BT, Stone RM. Making a case for anterior inferior iliac spine/subspine hip impingement: Three representative case reports and proposed concept. Arthrosc - J Arthrosc Relat Surg. 2011;27(12): 1732-1737. Available from: http://dx.doi.org/10.1016/j. arthro.2011. 10.004

10. Sutter R, Pfirrmann CWA. Atypical hip impingement. Am J Roentgenol. 2013;201(3):437-442.

11. Gamradt SC, Brophy RH, Barnes R, Warren RF, Thomas Byrd JW, Kelly BT. Nonoperative treatment for proximal avulsion of the rectus femoris in professional American football. Am J Sports Med. 2009 Jul 30;37(7):1370-1374. Available from: http://journals.sagepub.com/doi/10.1177/ 0363546509333477

12. Rossi F, Dragoni S. Acute avulsion fractures of the pelvis in adolescent competitive athletes: prevalence, location and sports distribution of 203 cases collected. Skeletal Radiol. 2001 Mar;30(3):127-131. Available from: http://www.ncbi.nlm.nih.gov/ pubmed/ 11357449

13. Matsuda DK, Calipusan CP. Adolescent Femoroacetabular Impingement From Malunion of the Anteroinferior Iliac Spine Apophysis Treated With Arthroscopic Spinoplasty. Orthopedics. 2012;90034:460-463. Available from: http://www.slackinc.com/doi/resolver.asp?doi=10. 3928/ 01477447-20120222-44

14. Hapa O, Bedi A, Gursan O, Akar MS, Güvencer M, Havitçioğlu $\mathrm{H}$, et al. Anatomic footprint of the direct head of the rectus femoris origin: Cadaveric study and clinical series of hips after arthroscopic anterior inferior iliac spine/subspine decompression. Arthrosc - J Arthrosc Relat Surg. 2013;29(12):1932-1940.

15. Amar E, Warschawski $Y$, Sharfman ZT, Martin HD, Safran MR, Rath E. Pathological findings in patients with low anterior inferior iliac spine impingement. Surg Radiol Anat. 2015 Nov 30; Available from: http://www.ncbi.nlm. nih.gov/pubmed/26620219

16. Moher D, Liberati A, Tetzlaff J, Altman DG, PRISMA Group. Preferred reporting items for systematic reviews and meta-analyses: the PRISMA statement. Ann Intern Med. 2009 Aug 18;151(4): 264-269, W64. Available from: http://www.ncbi. nlm.nih. gov/pubmed/19622511

17. Padulo J, Oliva F, Frizziero A, Maffulli N. Muscles, Ligaments and Tendons Journal - Basic principles and recommendations in clinical and field science research: 2016 update. MLTJ; 2016;6(1):1-5.

18. Hetsroni I, Larson CM, Dela Torre K, Zbeda RM, Magennis E, Kelly BT. Anterior inferior iliac spine deformity as an extra-articular source for hip impingement: A series of 10 patients treated with arthroscopic decompression. Arthrosc - J Arthrosc Relat Surg. 2012;28(11):1644-1653. Available from: $h$ ttp://dx.doi.org/10.1016 /j.arthro.2012. 05.882

19. Nabhan DC, Moreau WJ, McNamara SC, Briggs KK, Philippon MJ. Subspine hip impingement: An unusual cause of hip pain in an elite weightlifter. Curr Sports Med Rep. 2016;15(5):315-319.
20. Nawabi DH, Degen RM, Fields KG, Wentzel CS, Adeoye O, Kelly BT. Anterior Inferior lliac Spine Morphology and Outcomes of Hip Arthroscopy in Soccer Athletes: A Comparison to Nonkicking Athletes. Arthrosc - J Arthrosc Relat Surg. 2017;33(4):758-765. Available from: http://dx.doi. org/10.1016/j.arthro.2016.10.019

21. Nwachukwu BU, Chang B, Fields K, Rinzler J, Nawabi DH, Ranawat AS, et al. Outcomes for Arthroscopic Treatment of Anterior Inferior lliac Spine (Subspine) Hip Impingement. Orthop J Sport Med. 2017;5(8): 2325967 11772310. Available from: http://journals. sagepub. com/doi/10.1177/2325967117723109

22. Pan H, Kawanabe K, Akiyama H, Goto K, Onishi E, Nakamura $\mathrm{T}$. Operative treatment of hip impingement caused by hypertrophy of the anterior inferior iliac spine. J Bone Jt Surg - Br Vol. 2008;90-B(5):677-679. Available from: http://www.bjj.boneandjoint.org.uk/cgi/doi/ 10.1302/0301620X.90B5.20005

23. Krueger DR, Windler M, Geßlein M, Schuetz M, Perka C, Schroeder $\mathrm{JH}$. Is the evaluation of the anterior inferior iliac spine (AlIS) in the AP pelvis possible? Analysis of conventional X-rays and 3D-CT reconstructions. Arch Orthop Trauma Surg. 2017;137(7):975-980.

24. Schindler BR, Venderley MB, Mikula JD, Chahla J, Dornan GJ, Turnbull TL, et al. Comparison of Radiographs and Computed Tomography for the Screening of Anterior Inferior lliac Spine Impingement. Arthrosc - J Arthrosc Relat Surg. 2017;33(4):766-772. Available from: http://dx.doi. org/10.1016/j.arthro.2016.10.018

25. Piccirilli E, Oliva F, Murè MA, Mahmoud A, Foti C Tarantino $U$, et al. Viscosupplementation with intra-articular hyaluronic acid for hip disorders. A systematic review and meta-analysis. Muscles Ligaments Tendons J. 2016;6(3):293-299. Available from: http://www.ncbi.nlm. nih.gov/pubmed/28066733

26. Lewis CL, Sahrmann SA. Acetabular labral tears. Phys Ther. 2006 Jan;86(1):110-121. Available from: http://www. ncbi.nlm.nih.gov/ pubmed/16386066

27. Rajasekhar C, Kumar KS, Bhamra MS. Avulsion fractures of the anterior inferior iliac spine: The case for surgical intervention. Int Orthop. 2001;24(6):364-365.

28. Ryan JM, Harris JD, Graham WC, Virk SS, Ellis TJ. Origin of the direct and reflected head of the rectus femoris: An anatomic study. Arthrosc - J Arthrosc Relat Surg. 2014;30 (7):796-802. Available from: http://dx.doi. org/10.1016/ j.arthro.2014.03.003

29. Amar E, Druckmann I, Flusser G, Safran MR, Salai M, Rath E. The anterior inferior iliac spine: Size, position, and location. An anthropometric and sex survey. Arthrosc - J Arthrosc Relat Surg. 2013;29(5):874-881. Available from: http://dx.doi.org/10.1016/j.arthro.2013.01. 023

30. Larson CM, Giveans MR, Samuelson KM, Stone RM, Bedi A. Arthroscopic Hip Revision Surgery for Residual Femoroacetabular Impingement (FAI). Am J Sports Med. 2014;42(8):1785-1790. Available from: http://journals. sagepub.com/doi/10.1177/0363546514534181 